\title{
A INSEGURANÇA ALIMENTAR NO RETORNO ÀS AULAS PRESENCIAIS NUM CENÁRIO DE NULIDADE DE SANEAMENTO BÁSICO ADEQUADO
}

\author{
FOOD INSECURITY IN RETUM TO PESENCIAL CLASSES IN A PROPER SANITAION \\ NULLITY SCENARIO
}

Bruno Luiz Silveira de Castro ${ }^{1}$

RESUMO: Contexto atual da pandemia propôs diversas mudanças no cotidiano do brasileiro. A mudança das aulas presenciais para aulas remotas e a permanência por muito tempo nesse modelo provocou ruídos na sociedade o que proporcionou a movimentação do governo federal para realização de protocolos de retorno às aulas presenciais. Entretanto, os protocolos partem do princípio de que a água utilizada na higienização das pessoas, alimentos e locais é tratada, o que não pode ser garantido em todo o território nacional, visto que existem diversos locais que não apresentam saneamento básico adequado. Somado a isso, estudos demonstram atividade gastrintestinal do SARS-CoV-2 o que pode indicar uma possível infecção fecal-oral. $O$ objetivo desta revisão bibliográfica é demonstrar que a transmissão fecal-oral do SARS-CoV-2 ainda não foi descartada e que precisa ter atenção para que em locais onde não há saneamento básico ou existe um saneamento básico ineficiente podem apresentar focos de infecção e reinfecção pelo contato com o vírus na água não tratada. Enquanto não for descartada totalmente a possibilidade da infecção fecal-oral da Covid-ı, não há como garantir segurança no retorno às aulas, mesmo que os protocolos sejam rígidos.

Palavras-chave: Ensino híbrido. Covid-ı9. Alimentação escolar.

ABSTRACT: Current context of the pandemic has proposed several changes in the daily life of Brazilians. The change from face-to-face classes to remote classes and the long period of time in this model caused social disruption, which led to the federal government to start a process to carry out protocols for returning to face-to-face classes. However, the protocols start from the idea that the water used to sanitize people, food and places is treated, which cannot be ensured throughout the national territory, since there are several places where there is not adequate basic sanitation. In addition, a study demonstrates the gastrointestinal activity of SARS-CoV-2, which may indicate a possible fecal-oral infection. The purpose of this bibliographic review is to demonstrate that the fecal-oral transmission of SARS-CoV-2

\footnotetext{
I Estudante do Programa de Pós-Graduação em Práticas de Desenvolvimento Sustentável - Mestrado Profissional - Instituto de Florestas - Universidade Federal Rural do Rio de Janeiro. E-mail: bruno.silveiracastro@hotmail.com
} 
has not yet been ruled out and the necessity to pay attention to places where there is no basic sanitation or inefficient basic sanitation, hence there may be outbreaks of infection and reinfection by getting in contact with the virus in untreated water. As long as the possibility of Covid-is fecal-oral infection is not completely ruled out, there is no way to guarantee a safe return to school, even if the protocols are strict.

Keywords: Hybrid teaching; Covid-ı;; School feeding.

\section{INTRODUÇÃO}

Atualmente o Mundo vem passando por momentos difíceis e o noticiário tem demonstrado que mesmo com o avanço da vacinação de vários países, outros ainda apresentam vacinação extremamente lenta (MENDONÇA, A., 202I) devido a diversos fatores, entre eles: o negacionismo por parte de seus Chefes de Estado (PALACIOS, 2020). Contudo, o cenário não poderia ser diferente, mais de um ano depois da Organização Mundial da Saúde (OMS) decretar pandemia a mesma faz mais vítimas ainda (WHO, 202I).

Os dados são alarmantes, países que sofreram com a segunda onda apresentam crescimento de casos e mortes maiores do que na primeira onda, Brasil e Estados Unidos, por exemplo (WLE, 202I ) e outros países já se preparam para a terceira onda como a França e a Itália (SEVILLANO; LINDE; BENITO, 202I). Além disso, novas variantes estão surgindo (FREITAS; GIOVANETTI; ALCANTARA, 2021) e a dita imunidade de rebanho não ocorreu porque a ausência de políticas públicas eficientes para o controle somadas a não adoção dessas pela sociedade (de forma geral) favoreceu a multiplicação do vírus e suas mutações, somente no Brasil já foram detectadas três variantes: uma em Manaus - AM (TOLEDO, 202I); uma em Sorocaba - SP (TOMAZELA, 202I) e outra em Belo Horizonte MG (MENDONÇA, H., 202I).

Medidas foram tomadas pelos governos de todas as esferas públicas e uma dessas medidas foi a mudança do regime escolar para o remoto num intuito de diminuir a exposição da clientela escolar ao vírus, pois a frequência escolar aumentaria significativamente a disseminação do SARS-CoV-2 (BRASIL, 2020a). Entretanto, não foi possível prever que o 
estado de calamidade pública duraria por tanto tempo o que proporcionou pressão sobre os governos para o retorno às aulas.

$\mathrm{O}$ retorno às aulas ocorreu em diversas cidades brasileiras, assumindo protocolos de higienização como trás os documentos propostos pelo governo brasileiro. Por mais que o governo federal desenvolva ações com protocolos rígidos de retorno às aulas com segurança, todos eles partem do princípio de que a água utilizada para a limpeza e desinfecção das mãos, dos alimentos e das superfícies é tratada, o que não é uma realidade brasileira (FÁVERO; CUNHA, 2019).

Partindo do supracitado e analisando os fatos com seriedade a que se pede, este tem por objetivo demonstrar que a transmissão fecal-oral do SARS-CoV-2 ainda não foi descartada e que precisa ter atenção para que em locais onde não há saneamento básico ou existe um saneamento básico ineficiente podem apresentar focos de infecção e reinfecção pelo contato com o vírus na água não tratada, pois foram encontradas manifestações gastrintestinais do agente etiológico da Covid-I9 em diferentes estudos (DING; LIANG, 2020; GU; HAN; WANG, 2020; WANG; TU; SHENG, 2020).

\section{METODOLOGIA}

A metodologia usada foi a revisão bibliográfica (CERVO; BERVIAN; SILVA, 2007) buscando informações pertinentes ao assunto em questão em artigos científicos, documentos da União, documentos internacionais como da UNESCO e da ONU, sites de internet que acompanham em tempo real o progresso da pandemia, além de reportagens sobre a realidade da sociedade brasileira, para ter sustentação e referência teórica.

A proposta é trazer para o debate através de fundamentação científica a necessidade de exploração da epidemiologia do agente etiológico SARS-CoV-2 e seu potencial de transmissão. E para isso demonstrar a dicotomia entre os protocolos propostos pelo governo federal que partem do princípio de que a água disponibilizada para toda a população brasileira é de fato tratada, sendo que na contramão a ausência de saneamento básico adequado é uma realidade de milhões de cidadãos. 


\section{DISCUSSÃO}

A sociedade brasileira, como outras, vem mudando cada vez mais sua cultura no que diz respeito ao perfil e estruturação familiar, construção de modelo, o que antes era formulado e entendido como um casal heterossexual com filhos, onde o homem promovia a fonte de renda da família através do emprego e a mulher cuidava dos filhos em casa, hoje em dia, não é mais assim para a grande maioria das famílias. Sabe-se que independentemente da orientação sexual do casal, ambos precisam trabalhar e contam com as escolas e as creches para deixarem seus filhos para que busquem juntos recursos para manutenção familiar ou até aquelas famílias que são formadas somente por homens ou mulheres que vivem só com seu ou seus filhos, também necessitam de um lugar para os deixarem no horário de expediente (FERREIRA, 202I).

Vale ressaltar que o desenvolvimento cognitivo da clientela durante às aulas presenciais é maior do que durante as atividades promovidas remotamente. Serem assistidos por profissionais que se formaram para desenvolver aquelas atividades laborais têm um retorno maior do que a dependência dos familiares (não especializados para isso) para essa realização (NEVES; VALDEGIL; SABINO, 2021; LIMA et al., 2021).

Com isso, buscando uma solução para esta demanda da população e automaticamente com mais pessoas trabalhando, maior a produção de capital, o governo federal movimentou-se através do Ministério da Educação (MEC) e realizou a produção do Guia de Implementação de Protocolos de Retorno das Atividades Presenciais nas Escolas de Educação Básica, no qual informa: "Este guia contém normas técnicas de segurança em saúde e recomendações de ações sociais e pedagógicas a serem observadas pelos integrantes da comunidade escolar [...]" (BRASIL, 202od. p. 4). Entre outros documentos, foram levados em consideração para a elaboração estratégica do Guia no que diz respeito à educação alimentar e nutricional e à segurança dos alimentos, os quais foram elaborados pelo Fundo Nacional de Desenvolvimento da Educação - FNDE (BRASIL, 1968) através do Programa Nacional de Alimentação Escolar - PNAE (BRASIL, 1955). 
O PNAE através de ações governamentais promove o repasse de valores divididos em Io parcelas por ano para que haja a cobertura dos 200 dias letivos. Esse valor destinado às prefeituras tem o intuito de proporcionar ações de educação alimentar e nutricional a estudantes de todas as etapas da educação básica, além da alimentação escolar (BRASIL, s.d.). Mesmo assim, neste cenário pandêmico o FNDE por meio do PNAE desenvolveu uma cartilha denominada: Recomendações para a execução do programa nacional de alimentação escolar no retorno presencial às aulas durante a pandemia da COVID-I9: educação alimentar e nutricional e segurança dos alimentos (BRASIL, 2020c).

$\mathrm{Na}$ cartilha supracitada foram desenvolvidos protocolos para higienização do ambiente escolar e superfícies, além da higienização das mãos e dos alimentos. A utilização da água corrente nesses processos é de fundamental importância porque a água corrente, após a esfregação das mãos, alimentos, superfície e ambientes com sabão líquido (de preferência neutro), promove a remoção física dos agentes patogênicos, incluindo o agente etiológico SARS-CoV-2 (BRASIL, 2020c).

Vale ressaltar as formas com que a Política Nacional de Alimentação e Nutrição PNAN (BRASIL, 2013), a Lei Federal II.346 de 2006 - LOSAN (BRASIL, 2006) e a Política Nacional de Segurança Alimentar e Nutricional - PNSAN (BRASIL, 2010) trabalham a questão do acesso a água potável e acesso ao saneamento básico de qualidade.

O PNAN reconhece que o acesso à água potável e saneamento básico são precários em determinadas regiões do Brasil e determina isso como ações para diminuição da desnutrição infantil como demonstra o trecho a seguir:

Apesar das diferenças entre os grupos étnicos e regiões geográficas, a maior redução das prevalências de desnutrição infantil se deu na Região Nordeste e nas populações mais pobres do país, sendo os principais fatores responsáveis por esses avanços: o aumento da escolaridade materna, o aumento da renda familiar, o maior acesso aos serviços da Rede de Atenção Básica de Saúde e a expansão do saneamento básico (BRASIL, 2013, p. 18).

A LOSAN disserta da seguinte maneira em seu artigo $4^{\circ}$, inciso I: 
[...] a ampliação das condições de acesso aos alimentos por meio da produção, em especial da agricultura tradicional e familiar, do processamento, da industrialização, da comercialização, incluindo-se os acordos internacionais, do abastecimento e da distribuição de alimentos, incluindo-se a água, bem como das medidas que mitiguem o risco de escassez de água potável, da geração de emprego e da redistribuição da renda (BRASIL, 2006).

Já a PNSAN afirma pelo menos quatro vezes em diferentes partes da redação do Decreto a importância do acesso à água de qualidade como no Artigo 3을 inciso VI: "promoção do acesso universal à água de qualidade e em quantidade suficiente, com prioridade para as famílias em situação de insegurança hídrica e para a produção de alimentos

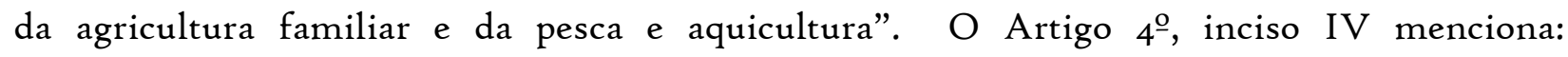
“incorporar à política de Estado o respeito à soberania alimentar e a garantia do direito humano à alimentação adequada, inclusive o acesso à água, e promovê-los no âmbito das negociações e cooperações internacionais". No Artigo 2I, Parágrafo 5ํㅡ, inciso IV: “acesso à alimentação adequada e saudável, incluindo água”. E o Artigo 22, inciso XII “acesso à água de qualidade para consumo e produção" (BRASIL, 20I0).

Em todos os processos desde o cultivo, manuseio, higienização e consumo próprio, a água está envolvida, visto isso, segundo a United Nations Educational, Scientific and Cultural Organization através do seu Relatório Mundial de Desenvolvimento Hídrico das Nações Unidas de 2021 (The United Nations World Water Development Report 2021) atribuir valor a água parece ser algo relativamente fácil, mas não é porque sem a água não existiria a vida que conhecemos (UNESCO, 202I).

O Brasil apresenta uma grande porcentagem de água doce líquida acessível em comparação com outros países e parece que essa sensação de grandes volumes (obviamente em regiões que o apresentam) promove um descaso para com seus devidos cuidados (REBOUÇAS, 2003). Isso não se reflete somente na sociedade, mas também nas ações dos Governos, pois ainda em relação ao saneamento básico mais de 57 milhões de residências estão sem acesso à rede de esgoto e 24 milhões estão sem água encanada (FÁVERO; CUNHA, 2019). Somando a esses dados alarmantes, já foram encontrados traços de SARS-CoV-2 no 
esgotamento sanitários de várias cidades tanto no Brasil, quando em outros países (MAGENTA, 2020).

Logo, na contramão do retorno às aulas presenciais com segurança, mesmo em cenário de pandemia, mesmo que praticando todos os protocolos cuidadosamente planejados, o ponto de partida é o princípio que a água que está sendo fornecida para as Escolas seja de qualidade ou melhor seja apropriada para o consumo humano e para a higienização do ambiente, superfícies e alimentos.

Seguindo a linha de pensamento de Silva e Leda (2012), é um paradoxo ensinar hábitos saudáveis de higiene e não ter o fornecimento adequado de água potável para que os alunos possam, por exemplo, lavar as mãos antes de se alimentarem. Além do contato direto com a água contaminada, outra forma de contágio é através da alimentação que muitas vezes é manuseada por quem não tem conhecimento das formas de transmissão (SILVA et al., 2015) ou é lavada com água contamina ou já encontram-se contaminados por falta de fiscalização da higiene desses produtos (CANTOS et al., 2004).

É preciso observar que dentro do Direito Humano à Alimentação Adequada - DHAA existem duas dimensões:

[...] o direito de estar livre da fome e o direito à alimentação adequada. A realização destas duas dimensões é de crucial importância para a fruição de todos os direitos humanos. Os principais conceitos empregados na definição de Direito Humano à Alimentação Adequada são disponibilidade de alimentos, adequação, acessibilidade e estabilidade do acesso a alimentos produzidos e consumidos de forma soberana, sustentável, digna e emancipatória (BRASIL, 2017).

Somente mencionar a necessidade de saneamento básico de qualidade diretamente ou indiretamente não promove ações concretas por aqueles que deveriam promovê-las (governos de todas as esferas de poder). O problema sanitário do Brasil é crônico e vem se arrastando através da história do país. É certo que muito já foi feito, mas para um país de dimensões continentais e de multiplicações desordenadas de habitações parece que um final feliz está muito longe de acontecer. 
A atual movimentação é o novo marco do saneamento básico que determina que até dezembro de 2033, 99\% da população terá acesso a água potável e $90 \%$ da população terá acesso a coleta e tratamento de esgoto (BRASIL, 2020b). Vale ressaltar que água potável e saneamento básico encontram-se como um dos objetivos do desenvolvimento sustentável ODS 6 para a Agenda 2030 o qual diz: "Assegurar a disponibilidade e gestão sustentável da água e saneamento para todos” (AGENDA 2030, 2015).

A preocupação com traços de SARS-CoV-2 no esgotamento sanitário deveria ser maior. A epidemiologia desse vírus demonstra que ele é transmitido através de contato direto ou indireto com secreções que o contenham (BULUT; KATO, 2020; WHO, 2021). Entretanto, a via fecal-oral não pode ser descartada porque há potencial para que ocorra devido a manifestações gastrintestinais do vírus (DING; LIANG, 2020; GU; HAN; WANG, 2020; WANG; TU; SHENG, 2020).

Outra informação importante é que o novo Coronavírus é fruto de mutação de alguma cepa que transitou por diferentes espécies de animais até atingir os seres humanos (BULUT; $\mathrm{KATO}$, 2020). E a permanência desse vírus em corpos d'água lênticos ou lóticos é determinante para que ele esteja disponível para infectar outros seres vivos e sofrer novas mutações e isso é uma possibilidade para lugares que não apresentam coleta e tratamento de esgoto (SOUZA et al., 202I). Sem contar que a ausência de saneamento básico em cidades que apresentam captação de água em locais que também apresentam despejo do esgotamento sanitário podem proporcionar infecções e reinfecções pelo contato dos seres humanos às cepas do vírus.

No Marco da FAO (Food and Agricultural Organization) para a Agenda Alimentar Urbana há a menção:

A segurança alimentar e a nutrição também se veem afetadas pela inocuidade dos alimentos consumidos e pela capacidade conexa do consumidor para fazer uso dos nutrientes e da energia que contém os alimentos. Nos contextos urbanos, as preocupações sanitárias aumentam devido à falta de instalações adequadas de água, saneamento e higiene (ONU, 2020, p. Io). 
Apesar de haver preocupação com a situação precária de diversas famílias, a informação supracitada ainda não levava em consideração a epidemiologia do SARS-CoV-2 e suas variantes mutagênicas.

\section{CONSIDERAÇÕES FINAIS}

A falta de noção da realidade sanitária do Brasil é perceptível nos documentos que buscam propor protocolos rígidos para o retorno às aulas presenciais. Basear-se numa realidade inexistente é extremamente perigoso, pois as populações menos favorecidas que serão as mais afetadas porque é no dia a dia delas que estão situação sanitárias precárias ou inexistentes.

O saneamento básico de qualidade não é a arma principal para o combate a pandemia, mas é uma delas. Além do mais, estações de tratamento de água e estações de tratamento de esgoto são necessárias para a vida do cidadão brasileiro, pois para exercer de fato a sua cidadania há de se ter acesso a serviços básicos, entre eles: água potável e esgoto tratado.

Obviamente que as enfermidades e infecções não se resumem às políticas de profilaxia,

remediação e combate à COVID-ı, mas vistas as causas e consequências socioeconômicas de uma pandemia que está longe de seu fim, é de fundamental importância que o potencial de transmissão fecal-oral da COVID-ı9 seja ressaltado até que evidências científicas a descartem totalmente. Só assim as duas dimensões do DHAA serão atendidas de fato e a população carente terá menos um fardo com o que se preocupar.

\section{REFERÊNCIAS BIBLIOGRÁFICAS}

AGENDA 2030. 2015. Plataforma Agenda 2030: Acelerando as transformações para a Agenda 2030 no Brasil. Disponível em: http://www.agenda2030.com.br/. Acesso em: 30 mar. 2021.

BRASIL. Decreto no 37.106, de 31 de março de 1955. Institui a companhia da Merenda Escolar. Disponível em: https://www2.camara.leg.br/legin/fed/decret/1950-1959/decreto-37106-31marco-I955-332702-publicacaooriginal-I-pe.html. Acesso em: 30 mar. 202I.

BRASIL. Decreto no 7.272, de 25 de agosto de 2010. Regulamenta a Lei n o II.346, de i5 de setembro de 2006, que cria o Sistema Nacional de Segurança Alimentar e Nutricional - 
SISAN com vistas a assegurar o direito humano à alimentação adequada, institui a Política Nacional de Segurança Alimentar e Nutricional - PNSAN, estabelece os parâmetros para a elaboração do Plano Nacional de Segurança Alimentar e Nutricional, e dá outras providências. Disponível em: https://www.gov.br/agricultura/pt$\mathrm{br} /$ assuntos/inspecao/produtos-vegetal/legislacao-I/biblioteca-de-normas-vinhos-ebebidas/decreto-no-7-272-de-25-de-agosto-de-2010.pdf/view. Acesso em: 30 mar. 2021.

BRASIL. Direito Humano à Alimentação Adequada. 2017. Disponível em: http://www4.planalto.gov.br/consea/acesso-a-informacao/institucional/conceitos/direitohumano-a-alimentacao-adequada. Acesso em: 30 mar. 2021.

BRASIL. Fundo Nacional de Desenvolvimento da Educação: Programa Nacional de Alimentação Escolar. Disponível em: https://www.fnde.gov.br/index.php/programas/pnae/pnae-sobre-o-programa/pnae-sobre-opnae. Acesso em: 30 mar. 202I.

BRASIL. 2020c. Fundo Nacional de Desenvolvimento da Educação. Programa Nacional de Alimentação Escolar. Recomendações para a execução do programa nacional de alimentação escolar no retorno presencial às aulas durante a pandemia da COVID-ı: educação alimentar e nutricional e segurança dos alimentos. Disponível em: https://www.fnde.gov.br/index.php/programas/pnae/pnae-area-gestores/pnae-manuaiscartilhas/item/13829-recomenda\% $\mathrm{C}_{3} \% \mathrm{~A}_{7} \% \mathrm{C}_{3} \% \mathrm{~B}_{5}$ es-para-a-execu\% $\mathrm{C}_{3} \% \mathrm{~A}_{7} \% \mathrm{C}_{3} \% \mathrm{~A}_{30}$-doprograma-nacional-de-alimenta\% $\mathrm{C}_{3 \% \mathrm{~A}} \% \mathrm{C}_{3} \% \mathrm{~A}_{30}$-escolar-no-retorno-presencial-\% $\mathrm{C}_{3} \% \mathrm{Aos}-$ aulas-durante-a-pandemia-da-covid-ı-educa $\% \mathrm{C}_{3} \% \mathrm{~A}_{7} \% \mathrm{C}_{3} \% \mathrm{~A}_{30}$-alimentar-e-nutricional-eseguran\% $\mathrm{C}_{3 \%} \mathrm{~A} 7 \mathrm{a}$-dos-alimentos. Acesso em: 30 mar. 2021.

BRASIL. Ministério da Educação. 202od. Guia de implementação de protocolos de retorno das atividades presenciais nas escolas de educação básica. Disponível em: https://www.gov.br/mec/pt-

$\mathrm{br} /$ assuntos/GuiaderetornodasAtividadesPresenciaisnaEducaoBsica.pdf. Acesso em: 30 mar. 2021.

BRASIL. Ministério da Educação. Portaria no 343, de 17 de março de 2020a: Dispões sobre a suspensão das aulas presenciais por aulas em meios digitais enquanto durar a situação de pandemia do Novo Coronavírus - COVID-i9. Disponível em: https://www.in.gov.br/en/web/dou/-/portaria-n-343-de-17-de-marco-de-2020-248564376.

Acesso em: 30 mar. 202I.

BRASIL. Ministério da Saúde. Secretaria de Atenção à Saúde. Departamento de Atenção Básica. Política Nacional de Alimentação e Nutrição / Ministério da Saúde, Secretaria de Atenção à Saúde. Departamento de Atenção Básica - I. ed., I. reimpr. - Brasília: Ministério da Saúde, 2013. $84 \mathrm{p}$. 
BRASIL. Lei $\mathrm{n}^{\mathrm{o}}$ 5.537, de 2i de novembro de 1968. Cria o Instituto Nacional de Desenvolvimento da Educação e Pesquisa (INDEP), e dá outras providências. Disponível em: http://www.planalto.gov.br/ccivil_03/LEIS/L5537.htm. Acesso em: 30 mar. 2021.

BRASIL. Lei no 1 Ir.346, de 15 de setembro de 2006. Cria o Sistema Nacional de Segurança Alimentar e Nutricional - SISAN com vistas em assegurar o direito humano à alimentação e dá outras providências. Disponível em: http://www.planalto.gov.br/ccivil_03/_ato20042006/2006/lei/lir346.htm. Acesso em: 30 mar. 2021.

BRASIL. Lei no 14.026 , de 15 de julho de 2020b. Atualiza o marco legal do saneamento básico e altera a Lei no 9.984, de 17 de julho de 2000, para atribuir à Agência Nacional de Águas e Saneamento Básico (ANA) competência para editar normas de referência sobre o serviço de saneamento, a Lei no 10.768 , de 19 de novembro de 2003, para alterar o nome e as atribuições do cargo de Especialista em Recursos Hídricos, a Lei no II.107, de 6 de abril de 2005, para vedar a prestação por contrato de programa dos serviços públicos de que trata 0 art. 175 da Constituição Federal, a Lei no 11.445 , de 5 de janeiro de 2007, para aprimorar as condições estruturais do saneamento básico no País, a Lei n- 12.305, de 2 de agosto de 2010, para tratar dos prazos para a disposição final ambientalmente adequada dos rejeitos, a Lei no 13.089, de I2 de janeiro de 2015 (Estatuto da Metrópole), para estender seu âmbito de aplicação às microrregiões, e a Lei no 13.529 , de 4 de dezembro de 2017, para autorizar a União a participar de fundo com a finalidade exclusiva de financiar serviços técnicos especializados. Disponível em: http://www.planalto.gov.br/ccivil_03/_ato2019-2022/2020/lei/li4026.htm. Acesso em: 30 mar. 2021.

BULUT, C.; KATO, Y. Epidemiolgy of COVID-19. Turkish Journal of Medical Sciences. 2020. 50: $\quad$ p. $563 \quad$ - $570 . \quad$ Disponível em: https://journals.tubitak.gov.tr/medical/abstract.htm?id=27232. Acesso em: 30 mar. 202I.

CANTOS, G. A. et al. Estruturas parasitárias encontradas em hortaliças comercializadas em Florianópolis, Santa Catarina. Newslab. v. 66. p. 154-163. 2004.

CERVO, A. L.; BERVIAN, P. A.; SILVA, R. Metodologia científica. 6 ed. São Paulo: Pearson Prentice Hall, 2007.

DING, S.; LIANG, T. J. Is SARS-CoV-2 Also an Enteric Pathogen With Potential FecalOral Transmission? A COVID-19 Virological and Clinical Review. Gastroenterology, 2020; v. I59: p. 53 - 6I. Disponível em: https://www.gastrojournal.org/article/Soor6-5085(20)30571o/fulltext. Acesso em: 30 mar. 2021.

FÁVERO, B.; CUNHA, A. R. 20I9. O saneamento básico no Brasil em 6 gráficos. Disponível em: https://www.aosfatos.org/noticias/o-saneamento-basico-no-brasil-em-6- 
graficos/\#: :text=A\%20situa\%C3\%A7\%C3\%A30\%20da\%2ocoleta\%2ode,segundo\%20a\%2oPna d\%20de\%202018.\&text=Segundo\%2odados\%20da\%20Snis\%20(Sistema,do\%2oesgoto\%20coleta do\%20\%C3\%A9\%2otratado. Acesso em: 30 mar. 202I.

FERREIRA, P. B. P. Educação e violência: ser professor é uma profissão de risco? Trabalho de conclusão de curso - TCC (Graduação) - Faculdade de Educação, Universidade Federal da Bahia. Salvador, p. 4I. 20Ir.

FRANCISCO. W. C. A distribuição de água no planeta. s. d. Disponível em: https://educador.brasilescola.uol.com.br/estrategias-ensino/a-distribuicao-agua-noplaneta.htm\#: :text=-\%2097\%25\%20da\%20\%C3\%Aigua\%20dispon\%C3\%ADvel\%20no,\%2029\%2 7 . Acesso em: 30 mar. 2021.

FREITAS, A. R. R.; GIOVANETTI, M.; ALCANTARA, L. C. J. Emerging variants of SARS-CoV-2 and its public health implications. InterAmerican Journal of Medicine and Health, 202I, 4. Disponível em: https://iajmh.com/iajmh/issue/view/ı2. Acesso em: 8 abr. 202I.

GU, J.; HAN, B.; WANG, J. COVID-ı: Gastrointestinal Manifestations and Potencial Fecal-Oral Transmission. Gastroenterology 2020; v. 158: p. 1518-1519. Disponível em: https://www.gastrojournal.org/article/Soor6-5085(20)3028I-

$\mathrm{X} /$ fulltext? referrer $=$ https\%3 $\mathrm{A} \% 2 \mathrm{~F} \% 2 \mathrm{Fwww}$.gastrojournal.org\%2F. Acesso em: 30 mar. 202I.

LIMA, S. P. N. et al. Challenges of the teaching-learning process in the face of the new coronavirus pandemic. Research, Society and Development, [S. l.], v. Io, n. I, p. e5521011174I, 202I. DOI: I0.33448/rsd-vioir.II74I. Disponível em: https://rsdjournal.org/index.php/rsd/article/view/II74I. Acesso em: 9 abr. 202I.

MAGENTA, M. 2020. Coronavírus em esgoto de 4 países antes do surto na China aumenta mistério sobre origem do vírus. BBC News Brasil. Disponível em: https://www.bbc.com/portuguese/internacional-533472II. Acesso em: 30 mar. 202I.

MENDONÇA, A. COVID-ı: 50 países já têm vacinação, Brasil segue atrasado; veja lista. Estado de Minas - Saúde. https://www.em.com.br/app/noticia/bemviver/2021/oI/o4/interna_bem_viver,1225874/covid-19-50-paises-ja-tem-vacinacao-brasilsegue-atrasado-veja-lista.shtml. Acesso em: 30 mar. 2021.

MENDONÇA, H. Pandemia de Coronavírus. Possível nova variante do Coronavírus é encontrada em Belo Horizonte, aponta estudo da UFMG: Cepa tem combinação de 18 mutações nunca anteriormente descritas de SARS-CoV-2, mas ainda não se sabe se causa maior transmissão do vírus. Minas Gerais vive escalada da doença e bateu recorde de mortes em 24 horas: foram notificados 508 óbitos. El País. Disponível em: 
https://brasil.elpais.com/brasil/202I-04-07/possivel-nova-variante-do-coronavirus-eencontrada-em-belo-horizonte-aponta-estudo-da-ufmg.html. Acesso em: 8 abr. 202I.

NEVES, V. N. S.; VALDEGIL, D. A.; SABINO, R. N. Ensino remoto emergencial durante a pandemia de COVID-r9 no Brasil: estado da arte. Práticas Educativas, Memórias e Oralidades - Rev. Pemo,[S. l.], v. 3, n. 2, p. e325271, 2021. DOI: 10.47149/pemo. v3i2.5271. Disponível em: https://revistas.uece.br/index.php/revpemo/article/view/5271. Acesso em: 9 abr. 202I.

PALACIOS, A. Os presidentes negacionistas da pandemia. Época. Disponível em: https://epoca.globo.com/ariel-palacios/coluna-os-presidentes-negacionistas-da-pandemia2435266r. Acesso em: 30 mar. 2021.

REBOUÇAS, A. C. Água no Brasil: abundância, desperdício e escassez. BAHIA ANÁLISE \& DADOS, Salvador, v. 13, n. ESPECIAL, p. 34I-345, 2003.

SEVILlANO, E. G.; LINDE, P.; BENITO, E. Pandemia de Coronavírus. Europa submerge em outra onda de covid-I9, impelida pelas novas variantes: Incidência aumentou $34 \%$ em três semanas. OMS alerta para a necessidade de não flexibilizar as medidas que evitam o contágio. El País. Disponível em: https://brasil.elpais.com/internacional/2021-03-20/europa-submergeem-outra-onda-de-covid-I9-impelida-pelas-novas-variantes.html. Acesso em 30 mar. 202I.

SILVA, A. O. et al. Epidemiologia e prevenção de parasitoses intestinais em crianças das creches municipais de Itapuranga-GO. Rev. Facul. Mont. Bel. v. 8, n. I, p. I-I7, 2014.

SILVA, T. V. DA; LEDA, L. R. Intervenções educativas sobre parasitoses intestinais: aplicação de um jogo para alunos do ensino fundamental. Saúde \& Amb. Rev., Duque de Caxias. v. 5, n. 2, p. 23-37, jul-dez. 2012.

SOUZA, L. C. et al. SARS-CoV, MERS-CoV e SARS-CoV-2: uma revisão narrativa dos principais Coronavírus do século. Brazilian Journal of Health Review, Curitiba, v.4, n.I, p.I4I9-I439 Jan/Feb. 2021. Disponível em: https://www.brazilianjournals.com/index.php/BJHR/article/view/23263. Acesso em: 8 abr. 202I.

TOMAZELA, J. M. Saúde. Variante sul-africana identificada em Sorocaba é mais transmissível e resistente, diz estudo: Cepa detectada pela primeira vez no Brasil tem comportamento parecido com a variante de Manaus. Estadão. Disponível em: https://saude.estadao.com.br/noticias/geral,variante-de-sorocaba-e-mais-transmissivel-eresistente-as-vacinas-contra-covid-diz-estudo,70003673624. Acesso em: 8 abr. 202I. 
TOLEDO, K. Medicina. Variante brasileira seria mais transmissível causaria reinfecção: Estudo sugere que a linhagem do Coronavírus de Manaus surgiu em novembro, e que se espalharia mais rapidamente, inclusive entre quem já pegou Covid-ı. Veja Saúde. Disponível em: https://saude.abril.com.br/medicina/variante-brasileira-seria-mais-transmissivel-ecausaria-reinfeccao/. Acesso em: 30 mar. 2021.

UNESCO - United Nations Educational, Scientific and Cultural Organization. The United Nations World Water Development Report 2021. Paris, 202I, p. 206. Disponível em: http://www.unesco.org/reports/wwdr/202I/en. Acesso em: 8 abr. 202I.

WANG, S.; TU, J.; SHENG, Y. Clinical characteristics and fecal-oral transmission potential of patients with COVID-19. medRxiv. 2020. 05. 02. 20089094. Disponível em: https://www.medrxiv.org/node/79571.external-links.html. Acesso em: 30 mar. 2021.

WORLD HEALTH ORGANIZATION - WHO. Timeline: WHO's COVID-I9 response. Disponível em: https://www.who.int/emergencies/diseases/novel-coronavirus2019/interactive-timeline\#event-7I. Acesso em: 30 mar. 2021.

WORLD HEALTH ORGANIZATION - WHO. Home. Health Topics. Coronavirus. Disponível em: https://www.who.int/health-topics/coronavirus\#tab=tab_I. Acesso em 30 mar. 2021.

WORLD LIFE EXPECTANCY - WLE. Live longer live better. Disponível em: https://www.worldlifeexpectancy.com/. Acesso em 30 mar. 2021. 